\section{Chromosome Numbers and Ploidy Levels of Chinese Curcuma Species}

Juan Chen ${ }^{1}$ and Nianhe Xia ${ }^{1}$

Key Laboratory of Plant Resources Conservation and Sustainable Utilization, South China Botanical Garden, Chinese Academy of Sciences, Guangzhou 510650 China

\section{Jietang Zhao, Jianjun Chen, and Richard J. Henny \\ University of Florida, IFAS, Mid-Florida Research and Education Center, 2725 S. Binion Road, Apopka, FL 32703}

Additional index words. hidden cone gingers, tumeric, Zingiberaceae

\begin{abstract}
Curcuma $\mathrm{L}$. is an economically important genus in the family Zingiberaceae. Many species are grown as medicinal, culinary, and ornamental crops. As a result of their high morphological diversity and small chromosome sizes, chromosome numbers and species relationships of Chinese Curcumas remain debated. This study examined chromosome numbers of 15 populations representing 11 species of Curcuma from China. Results showed that only Curcuma flaviflora S. Q. Tong was diploid with $2 n=2 x=42$ and C. kwangsiensis S. G. Lee \& C. F. Liang was tetraploid with $2 n=4 x=84$. The other species were triploid $(2 n=3 x=63)$. The study indicated that the basic chromosome number of Curcuma from China could be $x=21$. The diploid $C$. flaviflora produced viable seeds, which was the main means for propagation. The tetraploid and the triploids produced no seeds and relied on rhizomes for propagation. Chromosome sizes of all species were small, ranging from 0.5 to $2.1 \mu \mathrm{m}$, which prevented karyotype analysis. The fact that nine of 11 species studied were triploid indicates that triploidy may have some type of competitive advantage over the diploid and tetraploid. In addition, the triploids are popular commercially because of abundant rhizome production and this may contribute to their wide distributions.
\end{abstract}

The genus Curcuma L. is a member of the family Zingiberaceae consisting of $\approx 80$ species distributed mainly in South and Southeast Asia with outposts in India and southern China (Larsen et al., 1998). Some species are also found in Australia and the South Pacific (Wu and Larsen, 2000). Curcuma species are important specialty crops produced as medicinal, culinary, and ornamental plants (Chen and Xia, 2011). For example, C. aromatica Salisb., C. kwangsiensis S. G. Lee \& C. F. Liang, C. phaeocaulis Valeton, C. sichuanensis X. X. Chen, C. wenyujin Y. H. Chen \& C. Ling, and C. zanthorrhiza Roxb. (Liu, 1985) are widely used as medicinal plants. C. long L. produces highly aromatic and antiseptic turmeric, which has been extensively used as a spice, a beauty care agent, and traditional medicine (Aggarwal et al., 2007). Some others are used as ornamental plants such as C. elata Roxb., which is popular as cut flowers (Škornicková et al., 2007).

Received for publication 8 Feb. 2013. Accepted for publication 19 Mar. 2013.

This research was supported by National Natural Science Foundation of China (Grant no. 31170185 and no. 31200161).

We are grateful to Drs. Qin-er Yang and Yuan Qiong for their technical assistance in conducting this research. We also thank Mr. Yushi Ye for his help during field work.

${ }^{1}$ To whom reprint requests should be addressed; e-mail chenjuan101@scib.ac.cn; nhxia@scib.ac.cn.
Table 1. A summary of somatic chromosome numbers studied in Curcuma species.

\begin{tabular}{|c|c|c|c|}
\hline Taxa & No. $(2 n)$ & Origin & Reference \\
\hline \multirow[t]{2}{*}{ C. aff. oligantha Trim. } & 42 & Thailand & Eksomtramage et al. (2002) \\
\hline & 40 & Thailand & Saensouk and Chantaranothai (2003) \\
\hline C. oligantha Trim. & 77 & India & Leong-Škorničková et al. (2007) \\
\hline \multirow[t]{2}{*}{ C. amarissima Roscoe } & 63 & Bangladesh & Islam (2004) \\
\hline & 63 & India & Leong-Škorničková et al. (2007) \\
\hline \multirow[t]{5}{*}{ C. aromatica Salisb. } & 42 & India & Raghavan and Venkatsubban (1943) \\
\hline & 63,86 & India & Ramachandran (1961) \\
\hline & 63 & China & Liu (1985) \\
\hline & 63 & Bangladesh & Islam (2004) \\
\hline & 42,63 & India & Leong-Škorničková et al. (2007) \\
\hline \multirow[t]{3}{*}{ C. elata Roxb. } & 63 & Bangladesh & Islam (2004) \\
\hline & 63 & India & Leong-Škorničková et al. (2007) \\
\hline & 63 & Thailand & $\begin{array}{l}\text { Soontornchainaksaeng and } \\
\text { Abantgawat-Jónsson (2011) }\end{array}$ \\
\hline \multirow[t]{7}{*}{ C. longa $\mathrm{L}$. } & 64 & Unknown & Sugiura (1936) \\
\hline & 62 & India & Raghavan and Venkatsubban (1943) \\
\hline & 32 & Japan & Sato $(1960)$ \\
\hline & 63 & India & Ramachandran (1961) \\
\hline & 63 & China & Liu (1985) \\
\hline & 63 & Bangladesh & Islam (2004) \\
\hline & 63 & India & Leong-Škorničková et al. (2007) \\
\hline C. kwangsiensis S. G. Lee & 64 & China & Liu (1985) \\
\hline \multirow[t]{2}{*}{ \& C. F. Liang } & 84 & China & Chen et al. (1988) \\
\hline & 84 & China & Huang et al. (2010) \\
\hline $\begin{array}{l}\text { C. nankunshanensis N. Liu, } \\
\text { X. B. Ye \& J. Chen }\end{array}$ & 84 & China & Ye et al. (2008) \\
\hline \multirow[t]{2}{*}{ C. phaeocaulis Valeton } & 63 & China & Liu (1985) \\
\hline & 63 & China & Zhao et al. (2011) \\
\hline \multirow{2}{*}{$\begin{array}{l}\text { C. rubrobracteata Škorničk. Sabu } \\
\text { \& Prasanthk. }\end{array}$} & 42 & India & Leong-Škorničková et al. (2007) \\
\hline & 63 & China & Chen and Xia (2010) \\
\hline C. viridiflora Roxb. & 42 & Bangladesh & Islam (2004) \\
\hline C. wenyujin Y. H. Chen \& C. Ling & 63 & China & Chen and Chen (1984) \\
\hline C. yunnanensis N. Liu \& C. Senjen & 63 & China & Liu (1985) \\
\hline \multirow[t]{2}{*}{ C. zanthorrhiza Roxb. } & 63 & China & Chen and Chen (1984) \\
\hline & 63 & India & Leong-Škorničková et al. (2007) \\
\hline \multirow[t]{2}{*}{ C. zedoaria (Christm.) Roscoe } & 63 & Bangladesh & Islam (2004) \\
\hline & 64 & India & Venkatasubban (1946) \\
\hline
\end{tabular}

No. $=$ chromosome number.
Despite their economic importance, disagreements on chromosome numbers of $\mathrm{Cur}$ cuma species still exists (Table 1). Somatic chromosome numbers of $2 n=40,42$, and 77 were documented for $C$. oligantha Trim. by Saensouk and Chantaranothai (2003), Eksomtramage et al. (2002), and LeongŠkorničková et al. (2007), respectively. The chromosome number of $C$. aromatica was reported to be $2 n=42$ (Leong-Škorničková et al., 2007; Raghavan and Venkatsubban, 1943), 63 (Islam, 2004; Leong-Škorničková et al., 2007; Liu, 1985; Ramachandran, 1961), or 86 (Ramachandran, 1961). Variation also occurs in reports of the basic chromosome number, including $x=21$ (Raghavan and Venkatsubban, 1943); $x=7$ or 8 (Sato, 1960); and $x=7$ (Leong-Škorničková et al., 2007). Thus far, $x=21$ appears to be considered acceptable as the basic chromosome number (Eksomtramage et al., 2002; Islam, 2004; Joseph et al., 1999; Ramachandran, 1961, 1969). The ambiguity in chromosome numbers may be partially explained by potential misidentification of species. Curcuma species identification has been difficult as a result of the lack of a comprehensive taxonomic revision and the existence of numerous closely related species (Chen and Xia, 2011). So far, the number of species has been estimated at 50 (Wu and Larsen, 2000), 80 (Larsen et al., 1998), and 120 (Leong-Škorničková et al., 
2007). High intra- and interpopulation variation also likely contributes to confusion in identification of Curcuma species (Chen and Xia, 2011).

There are $\approx 12$ Curcuma species in China, mainly distributed in Yunnan, Guangxi, Sichuan, Guangdong, and Zhejiang provinces (Wu and Larsen, 2000). Somatic chromosome numbers of some Chinese Curcumas have been examined. Liu (1985) reported $2 n=63$ for C. aromatica, C. longa L., C. phaeocaulis, and $C$. yunnanensis N. Liu \& C. Senjen and $2 n=64$ for $C$. kwangsiensis. In contrast, Chen et al. (1988) stated $2 n=84$ for $C$. kwangsiensis. Chromosome numbers of other Chinese Curcumas have not been documented such as C. flaviflora S. Q. Tong and C. sichuanensis.

Chromosome numbers and ploidy levels are important information for plant taxonomy, genetics, and evolution as well as essential for plant conservation and use (Bennett and Leitch, 2005). Cytogenetic characters have also been considered critical for defining intrageneric groups in Curcuma (Islam, 2004; Joseph et al., 1999; Leong-Škorničková et al., 2007; Ramachandran, 1961). To pursue a better understanding of Chinese Curcuma species, this study was intended to examine chromosome numbers of available Curcuma species in China, their ploidy levels, and their implications in distribution.

\section{Materials and Methods}

For this study, nine populations across eight species were collected from the wild in southwestern China. Six individuals of four species from Guangxi Botanical Garden of Medicinal Plants and South China Botanical Garden, Chinese Academy of Sciences, were examined (Table 2). Collected plants were grown outdoors in the ginger garden or were cultivated in containers in a greenhouse at the South China Botanical Garden. The plant specimens were identified with the help of Dr. De-Lin Wu at the South China Botanical Garden. Herbarium acronyms followed Index Herbariorum (Holmgren et al., 1990). Taxonomic names were in accordance with the classifications of $\mathrm{Wu}$ and Larsen (2000).

Actively growing root tips of the collected plants were taken and pretreated with $2.0 \mathrm{~mm}$ 8-hydroxyquinoline for $6 \mathrm{~h}$, fixed in Carnoy I (three parts absolute ethanol and one part glacial acetic acid), macerated in $1 \mathrm{M} \mathrm{HCl}$ at $60{ }^{\circ} \mathrm{C}$ for $5 \mathrm{~min}$, and stained with Carbol fuchsin. The root tips were squashed with forceps in a drop of $45 \%$ acetic acid on a glass slide, covered with a cover glass, and squashed again. Cover glasses were removed by freezing glass slides in liquid nitrogen. Slides were dried at room temperature and passed through three solutions: absolute ethanol; 1:1 ethyl ethanol:xylene; and xylene. Slides were sealed with permount mounting medium. Metaphase chromosomes were observed and photographs were taken under the OLYMPUS BX41 microscope (Olympus, Tokyo, Japan). Eight individual root tips from different plants of each Curcuma collection were studied. Chromosome numbers of a minimum of 20 cells of each collection were counted at the well-spread metaphase stage. Ploidy levels were determined based on $x=21$ (Eksomtramage et al., 2002; Joseph et al., 1999; Ramachandran, 1961, 1969). All microscope slides were deposited in the South China Botanical Garden.

Reproductive strategies of different species were closely monitored and recorded, including seed propagation and asexual rhizome propagation. Seeds, if present, were collected and sowed. Rhizomes were also used for propagation.

\section{Results}

Chromosome numbers of 11 Curcuma species were determined (Table 2). Among them, C. amarissima Roscoe, C. aromatica, C. gulinqingensis N. H. Xia \& J. Chen, $C$. elata, C. sichuanensis, C. phaeocaulis, $C$. rubrobracteata, $C$. wenyujin, and $C$. zanthorrhiza had the chromosome number $2 n=63$

Table 2. Chromosome numbers and vouchers of 11 species of Curcuma from China.

\begin{tabular}{|c|c|c|c|c|c|c|}
\hline Scientific name & Habitat & Voucher & No. $^{z}(2 n)$ & Ploidy level $(x)$ & $\mathrm{LR}^{\mathrm{y}}(\mu \mathrm{m})$ & $\mathrm{RS}^{\mathrm{x}}$ \\
\hline $\begin{array}{l}\text { Curcuma rubrobracteata Škorničková, } \\
\text { M. Sabu \& Prasanthk. }\end{array}$ & $\begin{array}{l}\text { Wild, growing in sand soil along the } \\
\text { road in Menghai, Yunnan }\end{array}$ & J. Chen 0843 (IBSC) & 63 & 3 & $0.5-1.3$ & $\mathrm{~A}^{\mathrm{w}}$ \\
\hline C. aromatica Salisb. & $\begin{array}{l}\text { Cultivated in dry soil in Guangxi } \\
\text { Botanical Garden of Medicinal } \\
\text { Plants, Guangxi }\end{array}$ & J. Chen 0812 (IBSC) & 63 & 3 & $0.8-1.8$ & A \\
\hline C. sichuanensis X. X. Chen & $\begin{array}{l}\text { Wild, growing beside streams } \\
\text { in Menghai, Yunnan }\end{array}$ & J. Chen 0850 (IBSC) & 63 & 3 & $0.8-1.8$ & A \\
\hline C. elata Roxb. & $\begin{array}{l}\text { Cultivated beside the road at } \\
\text { South China Botanical Garden, } \\
\text { Guangdong }\end{array}$ & J. Chen 0813 (IBSC) & 63 & 3 & $1.0-1.8$ & A \\
\hline C. wenyujin Y. H. Chen \& C. Ling & $\begin{array}{l}\text { Cultivated beside the road } \\
\text { at South China Botanical } \\
\text { Garden, Guangdong }\end{array}$ & J. Chen 0806 (IBSC) & 63 & 3 & $0.8-1.8$ & A \\
\hline C. phaeocaulis Valeton & $\begin{array}{l}\text { Wild, growing beside streams } \\
\text { in Wenshan, Yunnan }\end{array}$ & J. Chen 0828 (IBSC) & 63 & 3 & $0.8-1.8$ & A \\
\hline C. gulinqingensis N. H. Xia \& J. Chen & $\begin{array}{l}\text { Wild, growing beside streams } \\
\text { in Wenshan, Yunnan }\end{array}$ & J. Chen 0826 (IBSC) & 63 & 3 & $0.6-1.3$ & A \\
\hline C. zanthorrhiza Roxb. & $\begin{array}{l}\text { Collected from the wild field, } \\
\text { Wenshan, Yunnan }\end{array}$ & J. Chen 20101 (IBSC) & 63 & 3 & $0.5-1.2$ & A \\
\hline C. flaviflora S. Q. Tong & $\begin{array}{l}\text { Wild at the margin of the forest } \\
\text { in Menghai, Yunnan }\end{array}$ & J. Chen 0885 (IBSC) & 42 & 2 & $0.5-2.1$ & $\mathrm{~S},{ }^{\mathrm{v}} \mathrm{A}$ \\
\hline C. amarissima Roscoe & $\begin{array}{l}\text { Wild, growing in sand soil along the } \\
\text { road in Menghai, Yunnan }\end{array}$ & J. Chen 0881 (IBSC) & 63 & 3 & $0.5-1.5$ & A \\
\hline C. kwangsiensis S. G. Lee \& C. F. Liang & $\begin{array}{l}\text { Wild, growing in sand soil along the } \\
\text { road in Menghai, Yunnan }\end{array}$ & J. Chen 0848 (IBSC) & 84 & 4 & $0.5-2.1$ & A \\
\hline C. kwangsiensis S. G. Lee \& C. F. Liang & $\begin{array}{l}\text { Collected from the wild field, } \\
\text { Baoshan, Yunnan }\end{array}$ & J. Chen 0849-1(IBSC) & 84 & 4 & $0.5-2.1$ & A \\
\hline C. kwangsiensis S. G. Lee \& C. F. Liang & $\begin{array}{l}\text { Cultivated in dry soil in Guangxi } \\
\text { Botanical Garden of Medicinal } \\
\text { Plants, Guangxi }\end{array}$ & - & 84 & 4 & $0.5-1.8$ & A \\
\hline C. kwangsiensis S. G. Lee \& C. F. Liang & $\begin{array}{l}\text { Cultivated in dry slope at South China } \\
\text { Botanical Garden }\end{array}$ & J. Chen 0816 (IBSC) & 84 & 4 & $0.5-1.8$ & A \\
\hline C. wenyujin Y. H. Chen \& C. Ling & $\begin{array}{l}\text { Cultivated in dry soil in Guangxi } \\
\text { Botanical Garden of Medicinal } \\
\text { Plants, Guangxi }\end{array}$ & J. Chen 0890 (IBSC) & 63 & 3 & $0.8-1.8$ & A \\
\hline
\end{tabular}

${ }^{\mathrm{z}}$ No. $=$ chromosome numbers.

${ }^{\mathrm{y}} \mathrm{LR}=$ chromosome length range.

${ }^{\mathrm{x}} \mathrm{RS}=$ reproduction strategies

${ }^{\mathrm{w}} \mathrm{A}=$ asexual reproduction.

${ }^{\mathrm{v}} \mathrm{S}=$ sexual reproduction. 
(Figs. 1A-H, 2J, and 2O), whereas $C$. kwangsiensis had $2 n=84$ (Fig. $2 \mathrm{~K}-\mathrm{N}$ ), and C. flaviflora had $2 n=42$ (Fig. 2I). All plants examined were polyploids except for $C$. flaviflora, which was a diploid. The ploidy levels of all species fitted well with the primary number $x=21$ (Figs. 1 and 2).

All chromosomes of the studied Curcuma were very small, ranging from 0.5 to $2.1 \mu \mathrm{m}$ in length; C. rubrobracteata (Fig. 1A) and $C$. zanthorrhiza (Fig. 2H) had the smallest chromosomes $(0.5-1.3 \mu \mathrm{m})$. As a result of the small chromosome sizes, no clear morphological differences were observed. Centromeres were difficult to detect; thus, karyotype analysis was not performed.
Our study showed that $C$. flaviflora produced viable seeds and rhizomes, but seeds were the main method for propagation (Table 2; Fig. 3A-C). Tetraploid C. kwangsiensis appeared not able to produce seeds in the South China Botanical Garden, so it was propagated through rhizomes (Table 2; Fig. $3 \mathrm{~F}-\mathrm{G}$ ) as were all of the triploids (Table 2; Fig. 3D-E).

The only diploid in the study, C. flaviflora, was found only in Yunnan province where it inhabits mountains or mountain margins. The majority of the triploids occurred in Southern China with the center of distribution in the Yunnan province. The tetraploids also had a wide geographical distribution, occurring in
Yunnan, Guangxi, and Guangdong provinces (Table 2; Fig. 4).

\section{Discussion}

This is the first report of chromosome counts for C. sichuanensis (Fig. 1C) and C. flaviflora (Fig. 2I). Before this study, no diploid chromosome counts have been reported for Chinese Curcumas (Chen and Chen, 1984; Chen et al., 1988; Liu, 1985). C. flaviflora produced viable seeds, which was the main method for propagation. The identification of $C$. flaviflora as a diploid species provided additional evidence supporting the claim that the basic chromosome number of

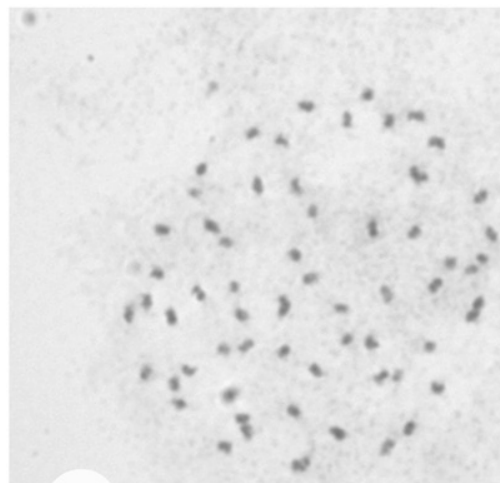

A
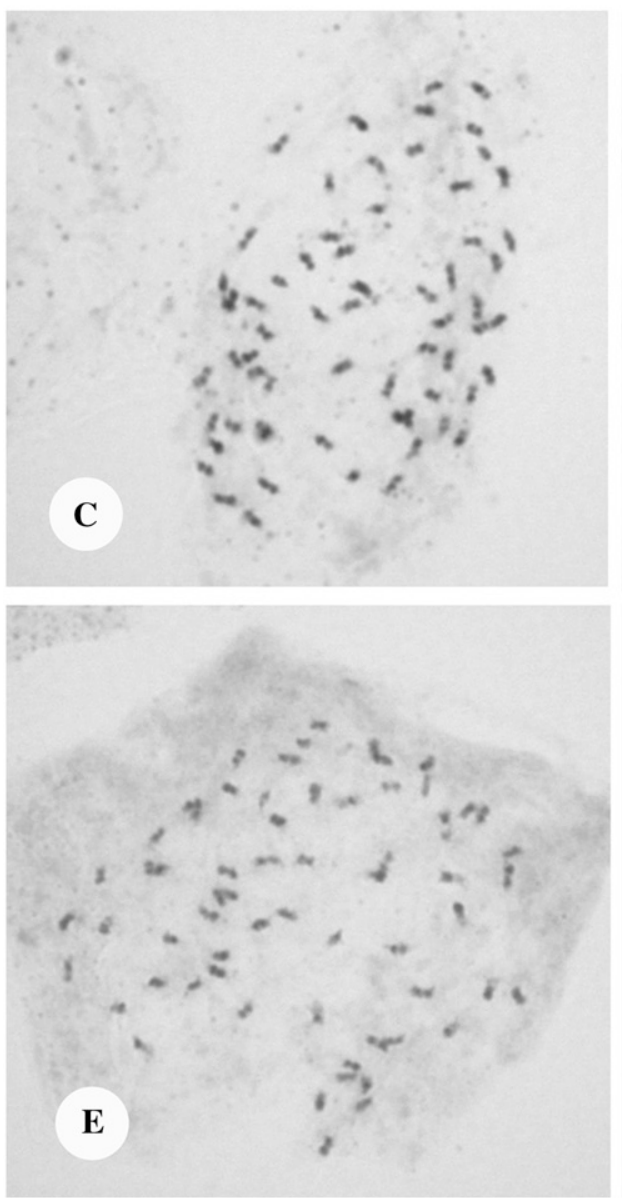
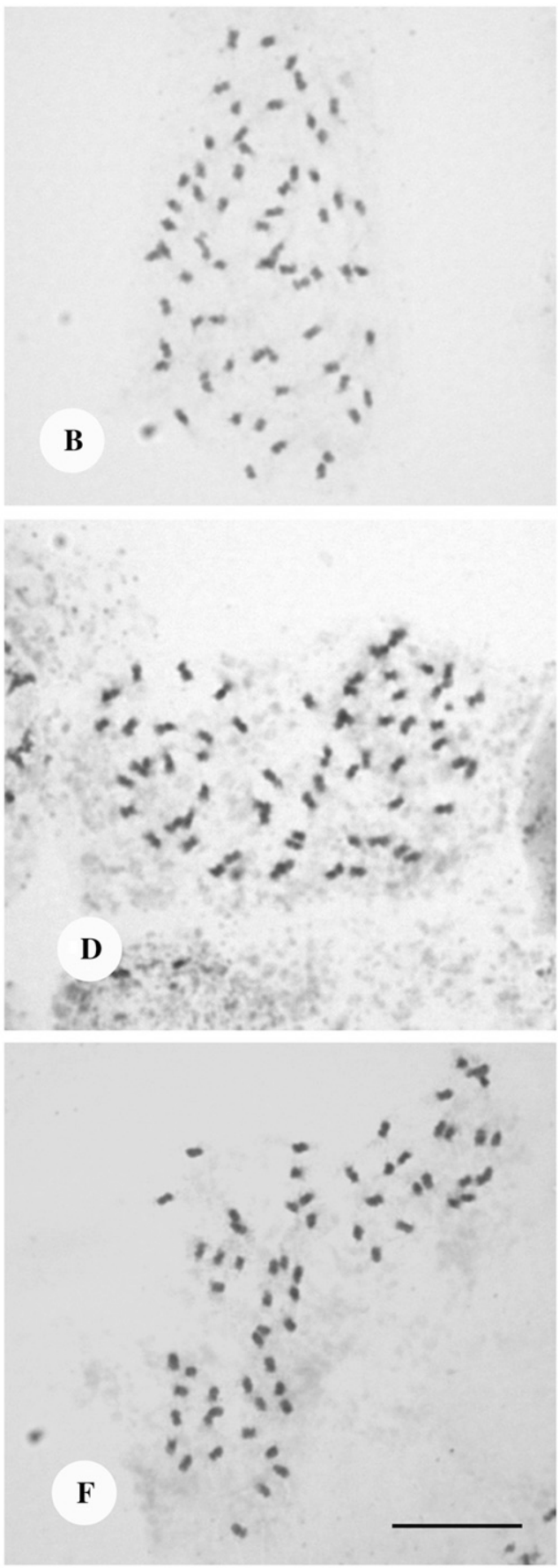

Fig. 1. Somatic metaphase chromosomes of Curcuma species. (A) Curcuma rubrobrateata $(2 n=63) ;$ (B) C. aromatica $(2 n=63) ;(\mathbf{C})$ C. sichuanensis $(2 n=63)$; (D) C. elata $(2 n=63)$; (E) C. wenyujin $(2 n=63)$; and (F) C. phaeocaulis $(2 n=63)$. Scale bar $=10 \mu \mathrm{m}$. 

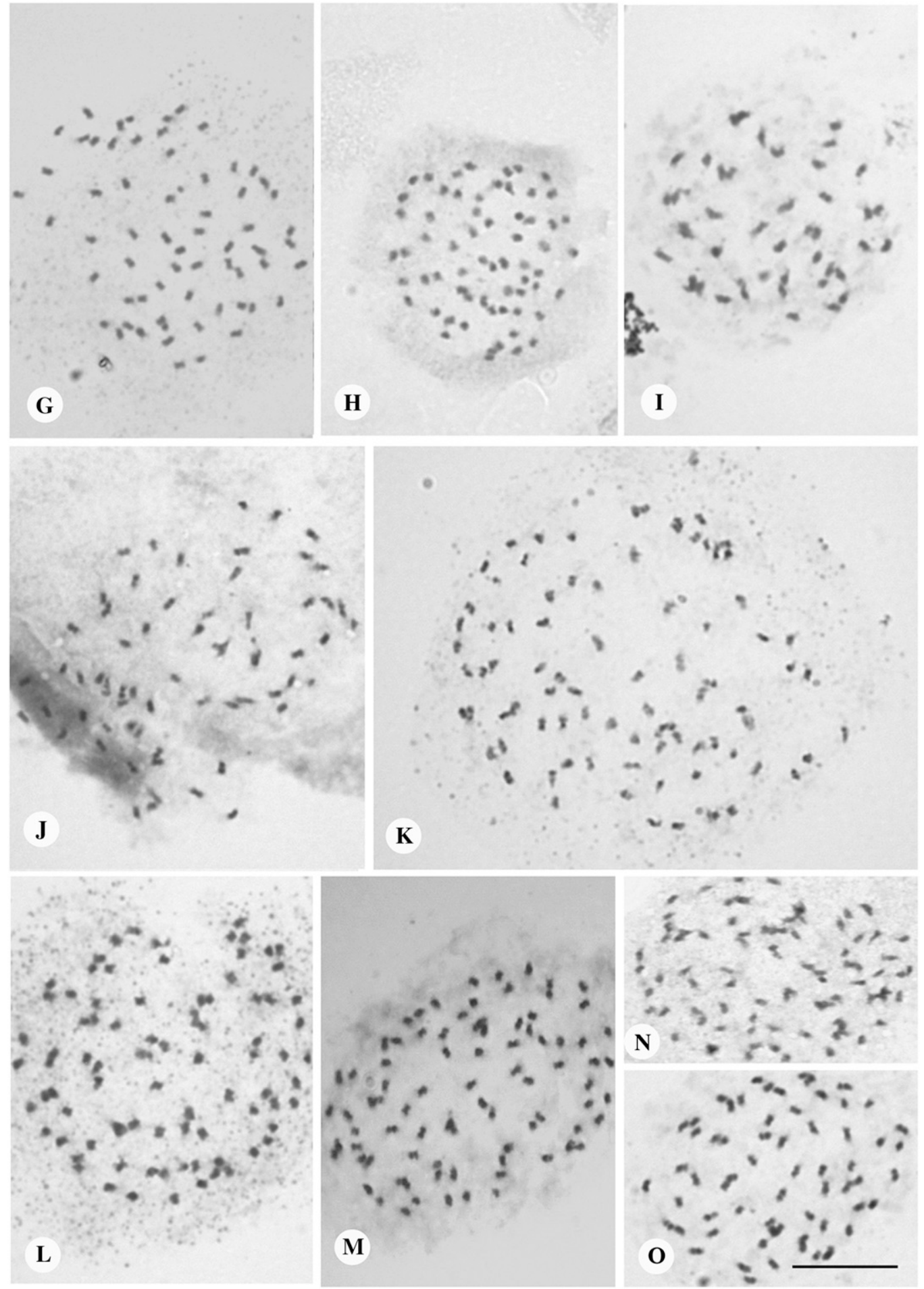

Fig. 2. Somatic metaphase chromosomes of Curcuma species. (G) Curcuma gulinqingensis $(2 n=63)$; (H) C. zanthorrhiza $(2 n=63)$; (I) C. flaviflora $(2 n=42)$; (J) C. amarissima $(2 n=63) ;(\mathbf{K})$ C. kwangsiensis $1(2 n=84) ;(\mathbf{L})$ C. kwangsiensis $2(2 n=84) ;(\mathbf{M})$ C. kwangsiensis $3(2 n=84) ;(\mathbf{N}) C$. kwangsiensis $4(2 n=$ 84); and (O) C. wenyujin $(2 n=63)$. Scale bar $=10 \mu \mathrm{m}$.

Curcuma was 21. Sharma and Bhattacharya (1958) first reported $x=16$ in the genus Curcuma. Sato (1960) proposed $x=7$ and $x=8$, and recently Leong-Škornicková et al. (2007) suggested that $x=7$ should be considered a primary basic chromosome number for at least the majority of Indian Curcuma species (subgenus Curcuma). This proposal was based on the chromosome count of $2 n=77$ in $C$. oligantha Trim by flow cytometry. On the other hand, the basic number $x=21$ appeared too high to be the primary one. Raghavan and Venkatsubban (1943), Ramachandran (1961), and Venkatasubban (1946) believed that this basic number might have been derived either by dibasic amphidiploidy (by combination of lower basic numbers of nine and 12 found in some genera in the family) or by secondary polyploidy. Nevertheless, the chromosome numbers of all 11 species in the present study can be explained by the basic chromosome number $x=21$.
The present study, in conjunction with an earlier investigation (Joseph et al., 1999), has demonstrated small and similar chromosome sizes in the genus Curcuma. Similar chromosome size was also prevalent in other genera characterized by $x=21$ such as Caulokaempferia yunnanensis (Gagnep.) Smith and Hitchenia (Chen et al., 1988; Leong-Škornicková et al., 2007; Ramachandran, 1969). The chromosomes of Curcuma were as small as those of other genera of the subfamily Zingiberoideae 

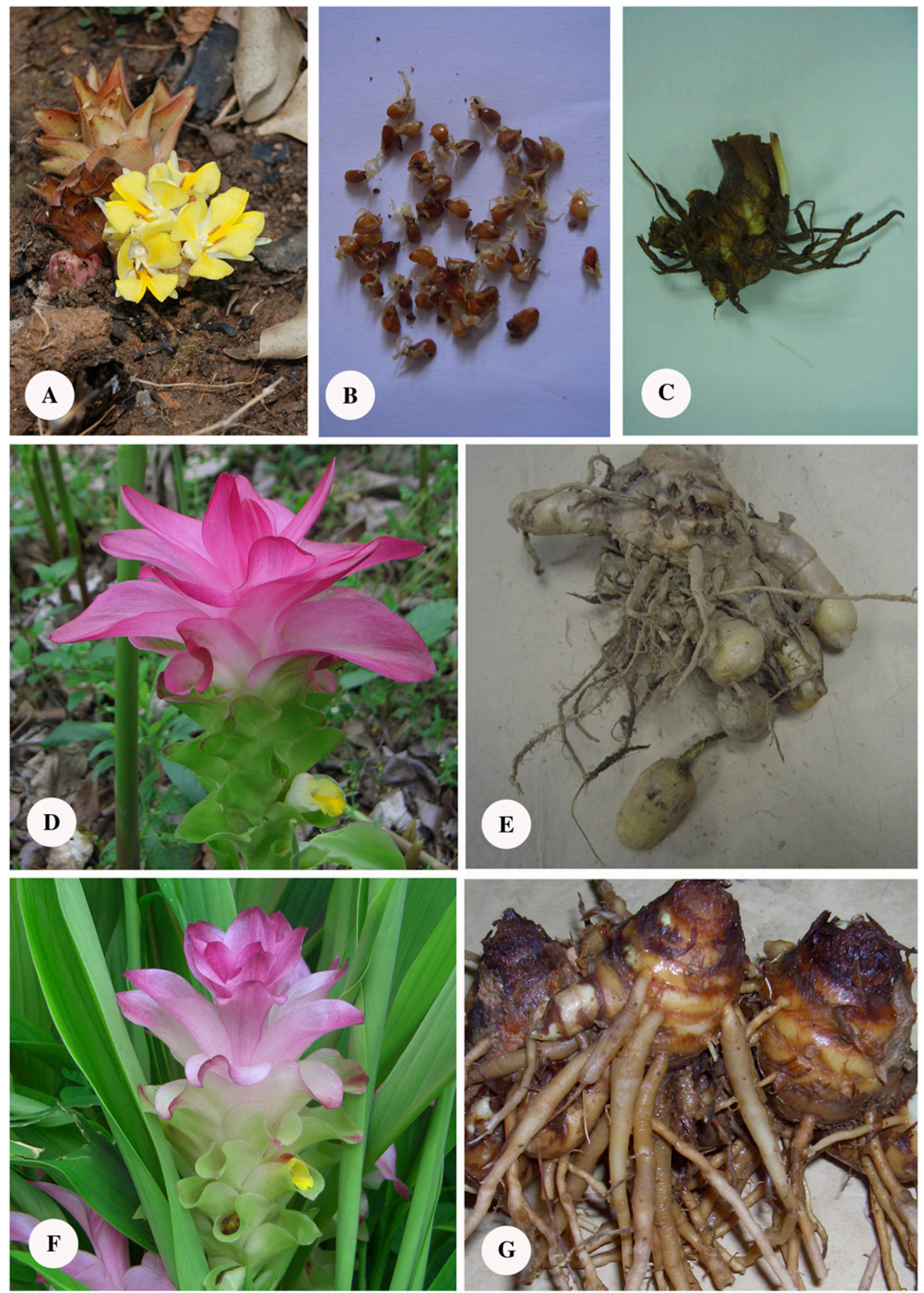

Fig. 3. Reproductive strategies of Curcuma species. (A-C) Spikes, seeds, and rhizomes of diploid species Curcuma flaviflora; (D-E) spikes and rhizomes of triploid species $C$. elata; and $(\mathbf{F}-\mathbf{G})$ spikes and rhizomes of tetraploid species $C$. kwangsiensis.

such as Globba, Hedychium and Cornukaempferia (Eksomtramage et al., 2002; Ramachandran, 1969). Stebbins (1966) pointed out that variation in chromosome size was correlated with climatic adaptation: the genera having smaller chromosomes were predominantly tropical or subtropical, whereas the large chromosomes were found exclusively in temperate climates. The genus Curcuma, one of many genera of the Zingiberaceae mainly occurring in tropical and subtropical habitats (Islam, 2004), may bear smaller chromosomes for adaptation to its habitat.

The triploids and tetraploids were located in areas either rich in water or influenced by human activities. Triploids probably originated by a fusion of reduced and unreduced gametes of diploids within or between species (LeongŠkornicková et al., 2007; Rieseberg and Willis, 2007). Given the continuum of traits in polyploid taxa, hybridization may have also played an important role (Rehse, 2005). Nevertheless, the fact that the majority of species in China were triploid indicates that triploids may have some type of competitive advantage over diploids and tetraploids. The triploids are sterile and do not require seed production, their abundant rhizomes (Fig. 3D-E) make them popular in production, and subsequent selection may contribute to their wide distribution. 


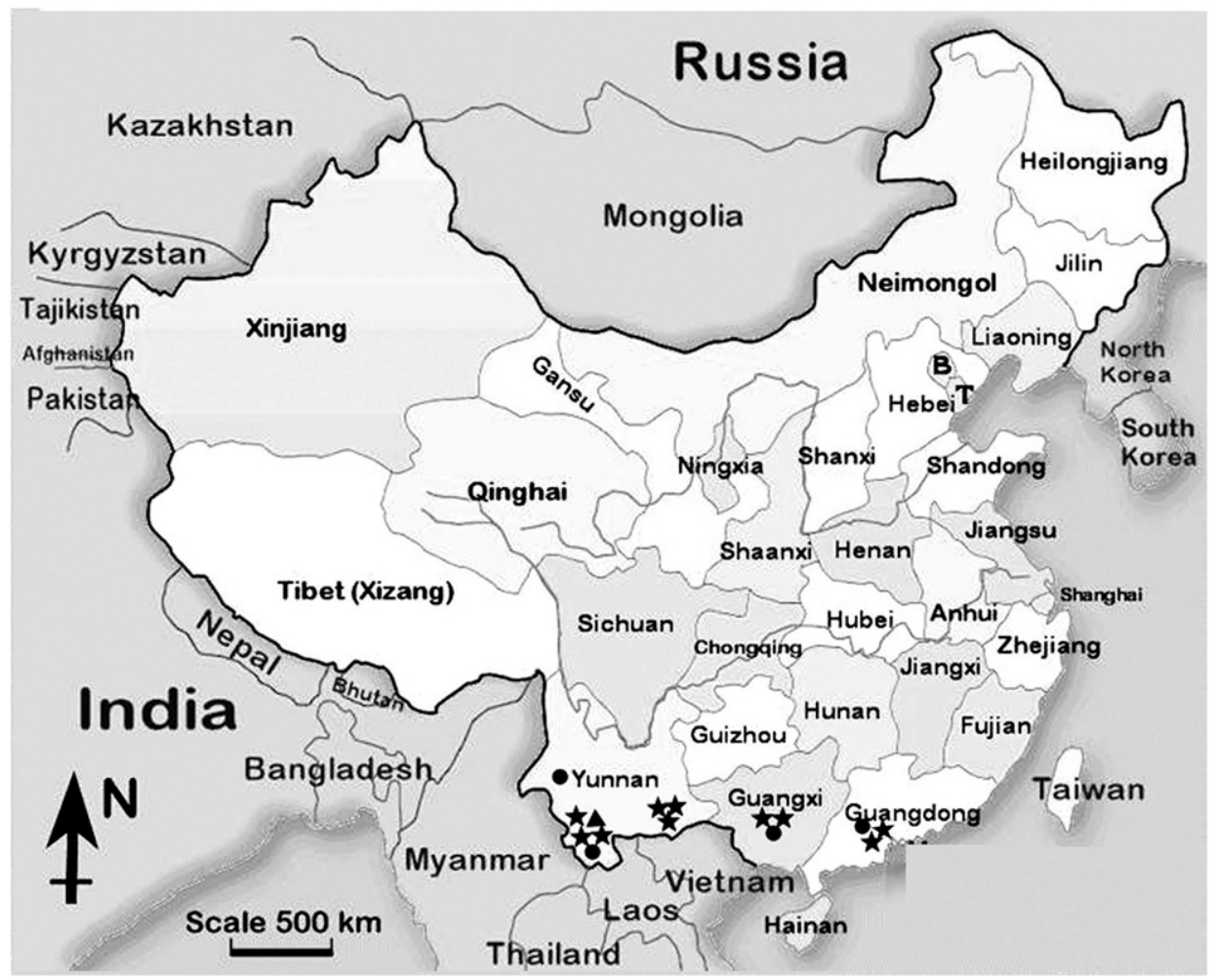

Fig. 4. The distribution of studied Curcuma in Guangdong, Guangxi, and Yunnan provinces, China. $\star$, species, respectively.

\section{Literature Cited}

Aggarwal, B.B., Y. Surh, and S. Shishodia. 2007. The molecular targets and therapeutic uses of curcumin in health and disease. Springer Science + Business Media, LLC, New York, NY.

Bennett, M.D. and I.J. Leitch. 2005. Nuclear DNA amounts in angiosperms: Progress, problems, and prospects. Ann. Bot. (Lond.) 95:45-90.

Chen, J. and N.H. Xia. 2010. Chromosome cytology, leaf epidermal morphology and palynology of Curcuma rubrobracteata (Zingiberaceae) Nord. J. Bot. 28:212-215.

Chen, J. and N.H. Xia. 2011. Pollen morphology of Chinese Curcuma L. and Boesenbergia Kuntz (Zingiberaceae): Taxonomic implications. Flora 206:458-467.

Chen, Z.Y. and S.J. Chen. 1984. A report on chromosome numbers of Chinese Zingiberaceae (2). Guihaia 4:13-18 [in Chinese with English summary].

Chen, Z.Y., S.J. Chen, X.X. Huang, and S.P. Huang. 1988. A report on chromosome numbers on Chinese Zingiberaceae (5). Guihaia 8:143147 [in Chinese with English summary].

Eksomtramage, L., P. Sirirugsa, P. Jivanit, and C. Maknoi. 2002. Chromosome counts of some Zingiberaceae species from Thailand. Songklanakarin. J. Sci. Technol. 24:311-319.

Holmgren, P.K., N.H. Holmgren, and L.C. Barnett (eds.). 1990. Index herbariorum. Part I, The herbaria of the world. 8th Ed. New York Botanic Garden, Bronx, NY.

Huang, J., Y.X. Zhao, X.H. Liu, and J. Wang. 2010 Chromosome karyotype analysis of Curcuma kwangsiensis. J. Anhui Agr. Sci. 38:1553815539 [in Chinese with English summary].

Islam, M.A. 2004. Genetic diversity of the genus Curcuma in Bangladesh and further biotechnological approaches for in vitro regeneration and long-term conservation of $C$. longa germplasm.
$\mathrm{PhD}$ thesis, University of Hannover, Hannover, Germany.

Joseph, R., T. Joseph, and J. Joseph. 1999. Karyomorphological studies in the genus Curcuma Linn. Cytologia (Tokyo) 33:313-317.

Larsen, K., J.M. Lock, H. Maas, and P.J.M. Maas. 1998. Zingiberaceae, p. 474-495. In: Kubitzki, $\mathrm{K}$. (ed.). The families and genera of vascular plants. Springer-Verlag, Berlin, Germany.

Leong-Škorničková, J., O. Sída, V. Jarolímová, M Sabu, T. Fér, P. Trávníček, and J. Suda. 2007. Chromosome numbers and genome size variation in Indian species of Curcuma (Zingiberaceae). Ann. Bot. (Lond.) 100:505-526.

Liu, N. 1985. The taxonomic study of Curcuma L. from China. MSc thesis, South China Botanical Garden, Guangzhou, China [in Chinese].

Raghavan, T.S. and K.R. Venkatsubban. 1943. Cytological studies in the family Zingiberaceae with special reference to chromosome number and cyto-taxonomy. Proc. Indian Acad. Sci. B 17:118-132.

Ramachandran, K. 1961. Chromosome numbers in the genus Curcuma. Linn. Curr. Sci. 30:194196.

Ramachandran, K. 1969. Chromosome numbers in Zingiberaceae. Cytologia (Tokyo) 34:213-221.

Rehse, T.M. 2005. Phylogenetics and classification of Curcuma (Zingiberaceae): Polyploidy, reticulation, and species complexes. MSc thesis, Duke University, Durham, NC.

Rieseberg, L.H. and J.H. Willis. 2007. Plant speciation. Science 317:910-914.

Saensouk, S. and P. Chantaranothai. 2003. The family Zingiberaceae in Phu Phan National Park. Proc. of the 3rd Symposium on the Family Zingiberaceae. Applied Taxonomic Research Centre, Khon Kean University, Khon Kaen, Thailand. p. 16-25.

Sato, D. 1960. The karyotype analysis in Zingiberales with special reference to the protokaryotype and stable karyotype. Sci. Papers Coll. Gen. Educ. Univ. Tokyo 10:225-243.

Sharma, A.K. and N.K. Bhattacharya. 1958. Cytology of several members of Zingiberaceae and a study of the inconstancy of their chromosome complements. Cellule 59:299-346.

Škornicková, J., T. Rehse, and M. Sabu. 2007. Other economically important Curcuma species, p. 451-467. In: Ravindra, P.N., K.N. Babu, and K. Sivaraman (eds.). Tumeric: The genus Curcuma (Medicinal and Aromatic PlantsIndustrial Profiles). Vol. 45. CRC Press, Taylor \& Francis Group, Boca Raton, FL.

Soontornchainaksaeng, P. and K. AnamthawatJónsson. 2011. Ribosomal FISH mapping reveals hybridity in phytoestrogen producing Curcuma species from Thailand. Plant Syst. Evol. 292:41-49.

Stebbins, G.L. 1966. Chromosomal variation and evolution. Science 152:1463-1467.

Sugiura, T. 1936. Studies on the chromosome number of higher plants. Cytologia (Tokyo) 7:544-595.

Venkatasubban, K.R. 1946. A preliminary survey of chromosome numbers in Scitamineae of Bentham \& Hooker. Proc. Indian Acad. Sci. B 23:281-300.

Wu, D.L. and K. Larsen. 2000. Zingiberiaceae, p. 322-377. In: Wu, Z.Y., P. Raven, and D.Y. Hong (eds.). Flora of China. Vol. 24. Science Press, Beijing, China, and Missouri Botanical Garden Press, St. Louis, MO.

Ye, X.B., J. Chen, and N. Liu. 2008. Curcuma nankunshanensis (Zingiberaceae), a new species from China. J. Trop. Subtrop. Bot. 16: 472-476.

Zhao, L.J., F.F. Tang, and L.K. Liu. 2011. Karyotype analysis of Curcuma zedoaria (Christm.) roscoe by using CPD staining and FISH with 45S rDNA. Chin. Agri. Sci. Bull. 27:190-194 [in Chinese with English summary]. 